Review

\title{
Magnesium Matrix Composite Foams-Density, Mechanical Properties, and Applications
}

\author{
Nikhil Gupta ${ }^{1, *}$, Dung D. Luong ${ }^{1}$ and Kyu Cho ${ }^{2}$
}

1 Composite Materials and Mechanics Laboratory, Department of Mechanical and Aerospace Engineering, Polytechnic Institute of New York University, Brooklyn, NY 11201, USA; E-Mail: ldzung01@students.poly.edu

2 USA Army Research Laboratory, Weapons and Materials Research Directorate, Aberdeen Proving Ground, MD 21005, USA; E-Mail: kyu.c.cho2.civ@mail.mil

* Author to whom correspondence should be addressed; E-Mail: ngupta@poly.edu; Tel.: +1-718-260-3080; Fax: +1-718-260-3532.

Received: 1 June 2012; in revised form: 29 June 2012 / Accepted: 3 July 2012 /

Published: 24 July 2012

\begin{abstract}
Potential of widespread industrial applications of magnesium has been realized in recent years. A variety of magnesium alloy matrix composites are now being studied for mechanical properties. Since magnesium is the lightest structural metal, it can replace aluminum in existing applications for further weight savings. This review presents an overview of hollow particle filled magnesium matrix syntactic composite foams. Fly ash cenospheres are the most commonly used hollow particles for such applications. Fly ash cenospheres primarily have alumino-silicate composition and contain a large number of trace elements, which makes it challenging to study the interfacial reactions and microstructure in these composites. Microstructures of commonly studied AZ and ZC series magnesium alloys and their syntactic foams are discussed. Although only a few studies are available on these materials because of the nascent stage of this field, a comparison with similar aluminum matrix syntactic foams has provided insight into the properties and weight saving potential of magnesium matrix composites. Analysis shows that the magnesium matrix syntactic foams have higher yield strength at the same level of density compared to most other metal matrix syntactic foams. The comparison can guide future work and set goals that need to be achieved through materials selection and processing method development.
\end{abstract}


Keywords: magnesium alloy; lightweight composite; automotive applications; syntactic foam

\section{Introduction}

Aluminum matrix composites have been widely studied in the published literature for interest in replacing steel based structures with these lighter materials [1-3]. In recent years aluminum matrix composites have found numerous applications in automotive, aviation, and consumer products $[4,5]$. The automotive sector has benefitted by replacing steel $(\sim 7.8 \mathrm{~g} / \mathrm{cc})$ with lower density aluminum $(\sim 2.7 \mathrm{~g} / \mathrm{cc})$ parts for weight saving. Magnesium, being the lowest density $(\sim 1.74 \mathrm{~g} / \mathrm{cc})$ structural metal, provides further opportunities of reducing weight.

\subsection{Automotive Weight Reduction}

The automotive sector is striving to find new solutions for weight reduction because of increasing awareness of pollution and rapidly tightening emission norms around the world [6]. Many countries are imposing stricter emission norms, which require auto companies to develop new technologies such as hybrid engines, electric engines, and increasing the efficiency of existing gasoline powered engines. An example of stricter emission norms proposed in the USA is the 2011 Corporate Average Fuel Economy or CAFE standard. For the small car class (footprint $<3.8 \mathrm{~m}^{2}$ ), the current fuel economy standard is 36 miles/gallon (mpg), which is required to increase to 41,49 , and $61 \mathrm{mpg}$ by the years 2016, 2020, and 2025, respectively. Compared to the year 2012, the fuel efficiency is required to increase by about $70 \%$ [7]. Such steep change requires exploring multiple options. In addition to improving engine technologies, weight reduction can play an important role in reducing the fuel consumption and maintenance cost of vehicles. Lighter cars require smaller engines, which further reduces their weight and improves fuel efficiency. Current automotive marketplace has moved towards calculating the total operating cost of cars, rather than just the initial cost, which provides a better justification for the use of lightweight composites. These composites may be initially more expensive but could provide significant savings over the life of the vehicle.

Magnesium, which is the lowest density structural metal, has been considered as a viable option to address the aforementioned issues such as weight reduction and fuel efficiency in automotive structures. Magnesium alloy wheels, engine blocks, and body panels have been tested by various manufacturers. Magnesium based automotive components are now available as standard components or aftermarket parts used for customization. Lightweight alloy wheels are a prominent example of application of magnesium in the automotive sector. High cost of magnesium has limited the current automotive applications only to high end cars such as Porsche, BMW, Jaguar and Corvette. Engine blocks of magnesium alloys have been used in several models of these makes. Race cars have now over 50 years of history of using magnesium alloys in auto body and engine blocks for weight reduction. Development of low cost processing methods and wider use of these alloys is expected to lower the cost and result in self-accelerated growth of this sector. Now there is also interest in replacing existing materials used in thermal management components with magnesium alloys and composites. The use of magnesium alloys in military vehicles is especially attractive for weight 
savings to accommodate heavy armor and improve maneuverability. Higher loading and towing capacity of vehicles can help in increasing the mission length and fuel carrying capacity, which are important for military applications.

Apart from the automotive sector, other consumer products are also made of magnesium. Several popular models of laptops have casings and batteries made of magnesium alloys for lightness and portability. The weight reduction of batteries is especially attractive to a number of applications, including electric vehicles.

\subsection{Syntactic Foams}

Syntactic foams are hollow particle filled porous composites [8,9]. These materials have been extensively studied during recent times to understand their structural property correlations and develop high performance varieties at low densities. Thin walled hollow particles are used in synthesizing syntactic foams. The ratio of inner to outer radius of hollow particles is over 0.9 in the commonly used hollow particles. Metal matrix syntactic foams (MMSF) with hollow particle volume fractions as high as $60 \%$ have been synthesized. Such high volume fraction leads to syntactic foam densities in the range $1-1.5 \mathrm{~g} / \mathrm{cc}$, which directly compete with polymer matrix composites. Their inherently high modulus, ductility, and melting points compared to that of polymers matrix composites result in very attractive properties of MMSFs.

Syntactic foams have been extensively studied for aluminum and polymer matrices [10-14]. Interest in magnesium foams is increasing in recent times due to their very low density [15-18]. Only a few studies are available on magnesium matrix syntactic foams [19,20]. Illustration of a syntactic foam microstructure is presented in Figure 1. Several phases exist in the microstructure as shown in the figure. The matrix voids may be undesirable because they adversely affect the strength and modulus of composites. However, in some cases, such voids may be intentionally used to obtain very low density composites. Stir mixing and pressure infiltration techniques are widely used for synthesizing MMSFs. Weak particles may break due to the processing conditions. The cavities of such particles may be filled with the alloy as seen in Figure 1. Synthesis methods need to be optimized to minimize the particle fracture and void entrapment to obtain high quality porous composites.

Figure 1. Schematic illustration of syntactic foam microstructure showing various phases and two types of voids.

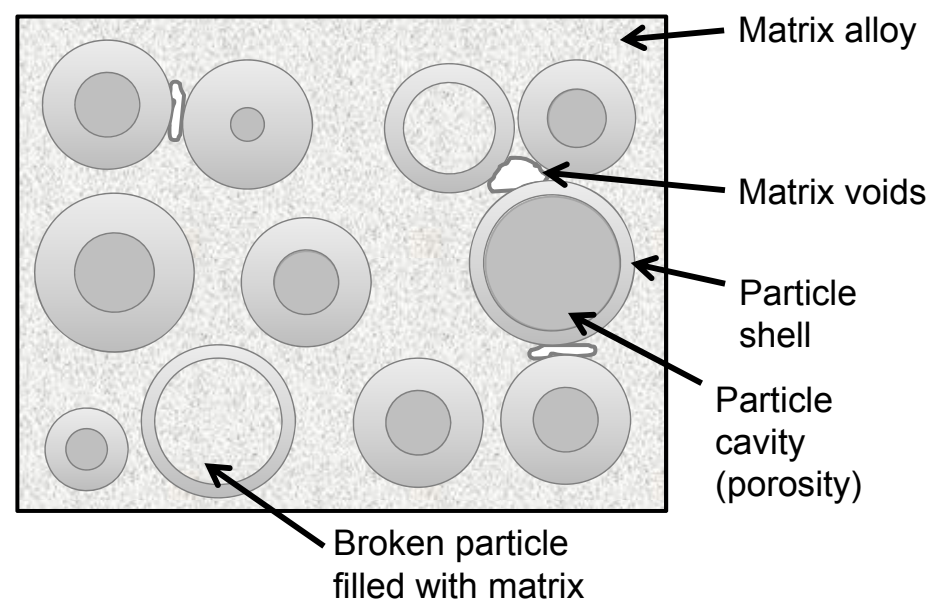


Fly ash cenospheres are the most widely used particles in syntactic foams due to their low cost. An example of cenospheres is presented in Figure 2a. Cenospheres are recovered from ash generated in thermal power plants. Cenospheres need to go through beneficiation processes to remove impurities and collect only the low density intact particles. Some of the cenospheres may have porosity embedded in their shell as seen in Figure 2b. Such porosity reduces their shell strength, which may lead to fracture during processing.

Figure 2. (a) Fly ash cenospheres; (b) Defects present in some cenospheres may include irregular shape, nonuniform wall thickness, and porous walls.

(a)

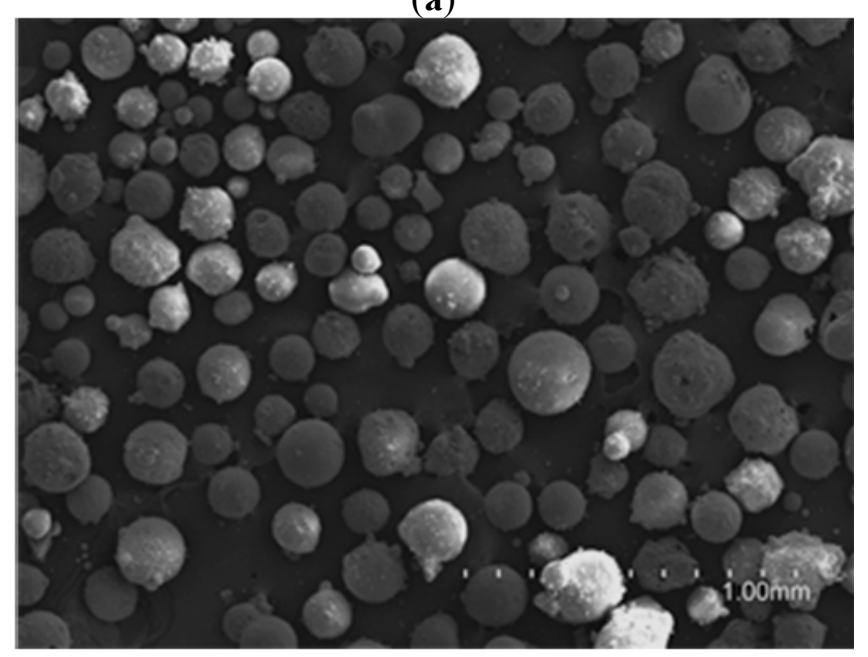

(b)

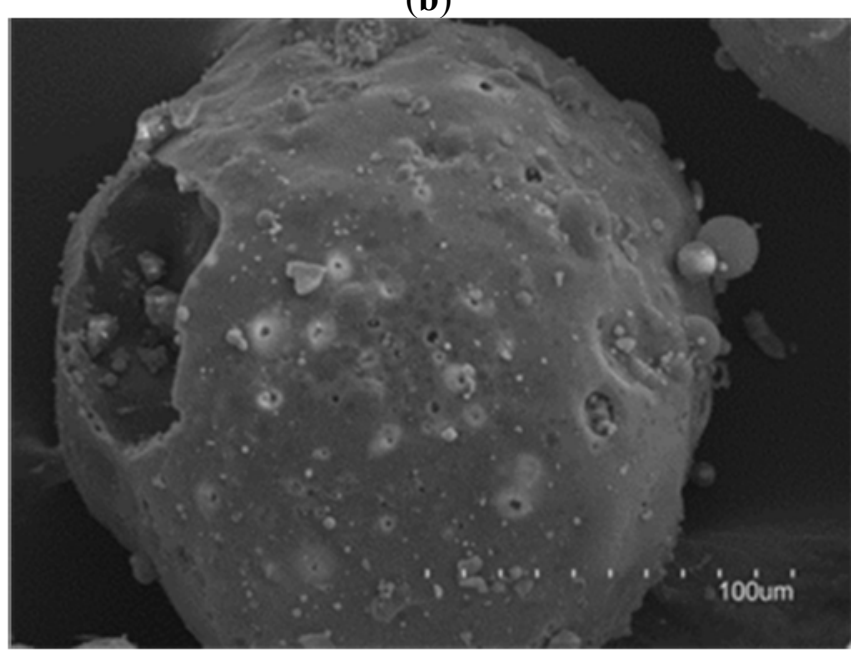

Hollow particles of alumina, silica, and silicon carbide have been used in some studies on MMSFs. An example of alumina hollow particles is shown in Figure 3a. High surface area of such particles (observed in Figure $3 \mathrm{~b}$ ) can provide advantage in improving interfacial bonding with the matrix material and result in strong bonding.

Figure 3. (a) Alumina hollow particle; and (b) the surface of the alumina particle (Courtesy Oliver M. Strbik III, Deep Springs Technologies, Toledo, OH, USA).

(a)

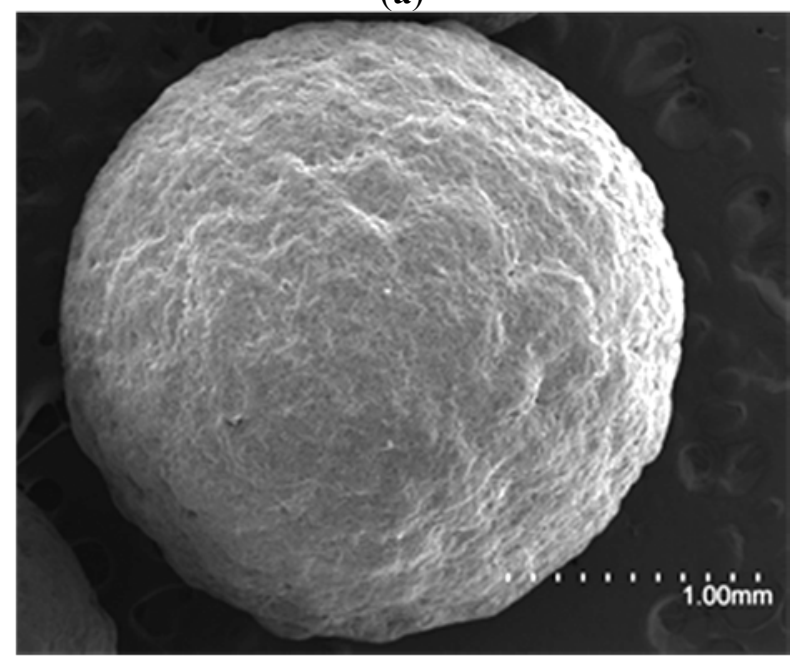

(b)

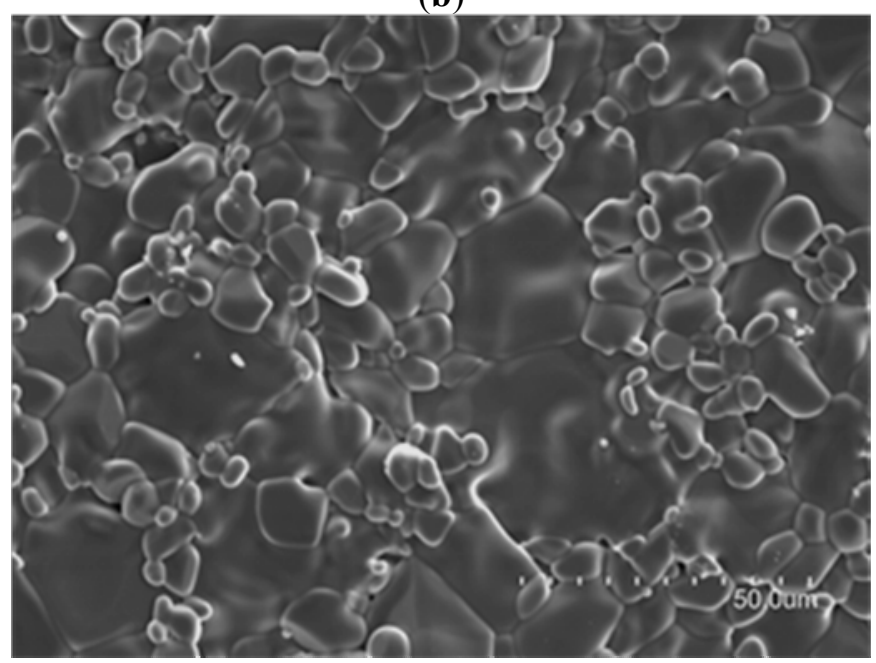


Hollow particles are now available in a wide size range, from nanometer to several millimeters $[21,22]$. In addition to lightweight composites, interest in hollow particles has been increasing for a variety of applications such as catalysts and several processes are now available for synthesizing such particles [23-25]. Usually engineered hollow particles have controlled structure and properties and offer better properties compared to fly ash cenospheres. In addition, their surfaces can be engineered to increase compatibility with the matrix metal or alloy.

\section{Microstructure}

A large variety of magnesium alloys are now available [26]. AZ and ZC series alloys are the most widely used in MMSFs. In the nomenclature of these alloys $\mathrm{A}, \mathrm{Z}$, and $\mathrm{C}$ refer to aluminum, zinc and copper, respectively. The two letters are followed by two numbers, which correspond to weight fractions of the respective alloying elements. Aluminum is the most common alloying element in magnesium. The Mg-Al phase diagram is of eutectic type, where the solvus line includes composition up to $12.6 \mathrm{wt} \% \mathrm{Al}$ and these alloys can be solution treated and aged. Addition of $\mathrm{Al}$ and $\mathrm{Cu}$ results in increased hardness and strength in $\mathrm{Mg}$ alloys. Both these elements tend to form intermetallic compounds in $\mathrm{Mg}$ alloys, which are responsible for increased hardness and strength. Nanoindentation studies have been carried out on AZ91 alloys, which show that the intermetallic precipitates have hardness and modulus of 3.8 and $71.3 \mathrm{GPa}$, respectively, compared to the hardness and modulus of surrounding matrix measured as 1.4 and $51.7 \mathrm{GPa}$, respectively [27]. Usually, the increased strength of $\mathrm{Mg}$ alloys due to the addition of $\mathrm{Al}$ or $\mathrm{Cu}$ comes at the expense of ductility. Addition of $\mathrm{Zn}$ along with $\mathrm{Al}$ and $\mathrm{Cu}$ helps in minimizing this problem.

The microstructure of AZ91D alloy commonly used in the fabrication of syntactic foams is shown in Figure 4. Precipitates of $\mathrm{Mg}_{17} \mathrm{Al}_{12}$ intermetallic, known as $\gamma$-phase, are seen in $\alpha$-solid solution in the microstructure. The precipitates are surrounded by a lamellar eutectic $\alpha+\gamma$ mixture. The precipitates are aluminum rich compared to the surrounding matrix. In this alloy system, $\mathrm{Mn}$ is also present in the matrix and the formation of precipitates of $\mathrm{Al}_{8} \mathrm{Mn}_{5}$ is also observed under appropriate conditions [28]. Similarly, the microstructure of $\mathrm{ZC} 63$ alloy shows $\alpha-\mathrm{Mg}, \mathrm{Mg}(\mathrm{Zn}, \mathrm{Cu})_{2}$ eutectic, $\mathrm{Cu}_{5} \mathrm{Zn}_{8}$ and $\mathrm{CuMnZn}$ [20]. In this work, it was determined that the microballoons and eutectic phases segregate at the $\mathrm{Mg}$ grain boundaries.

Figure 4. Optical micrographs of AZ91 alloy at two different magnifications.

(a)

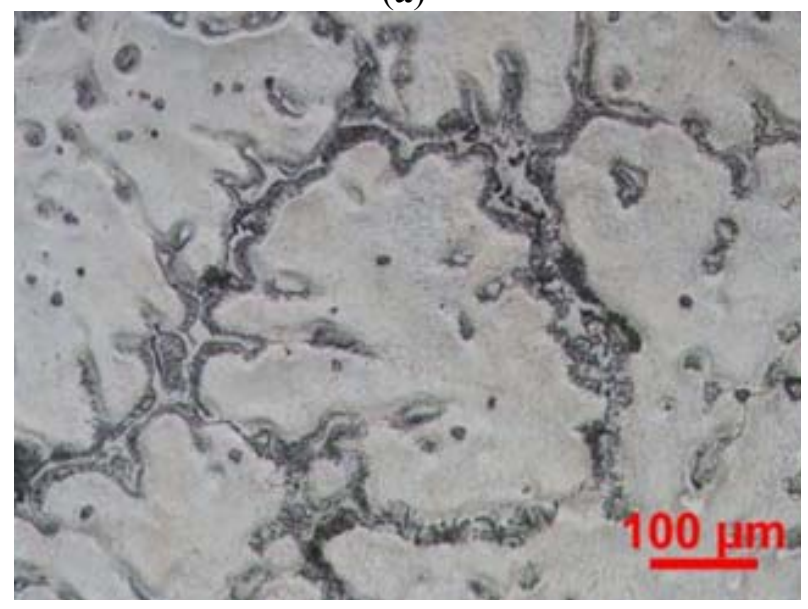

(b)

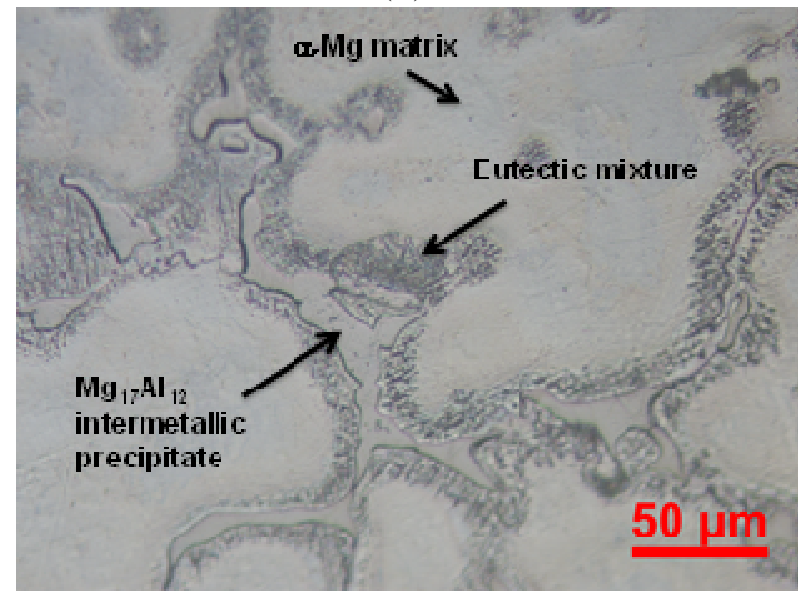


The AZ91D/cenosphere composite microstructure is shown in Figure 5. This microstructure can be compared with the schematic presented in Figure 1 to identify various phases. Matrix voids are not visible in the microstructure. However, broken cenospheres filled with matrix alloy during synthesis can be observed. A closer view at the particle and the matrix microstructure is shown in Figure 6 . The precipitates are usually aligned along the grain boundaries of the matrix. In these composites the defects present in the particle walls (Figure 7) can dominate the mechanical properties and failure mechanisms. It has been shown that during solidification processing, the difference in the thermal conductivity and heat diffusivity of fly ash and magnesium alloy causes the cenospheres to be at higher temperature than the surrounding matrix [20]. Nucleation does not start at the cenosphere surface due to higher temperature of cenospheres. The latent heat of fusion released during solidification further reduces the rate of solidification in the cenosphere vicinity and the cenospheres are pushed to the interdendritic region and reside at the grain boundaries. The reactions at the AZ91D/cenosphere interface have been studied [29].

Figure 5. Optical micrograph of AZ91D/fly ash cenosphere composite.

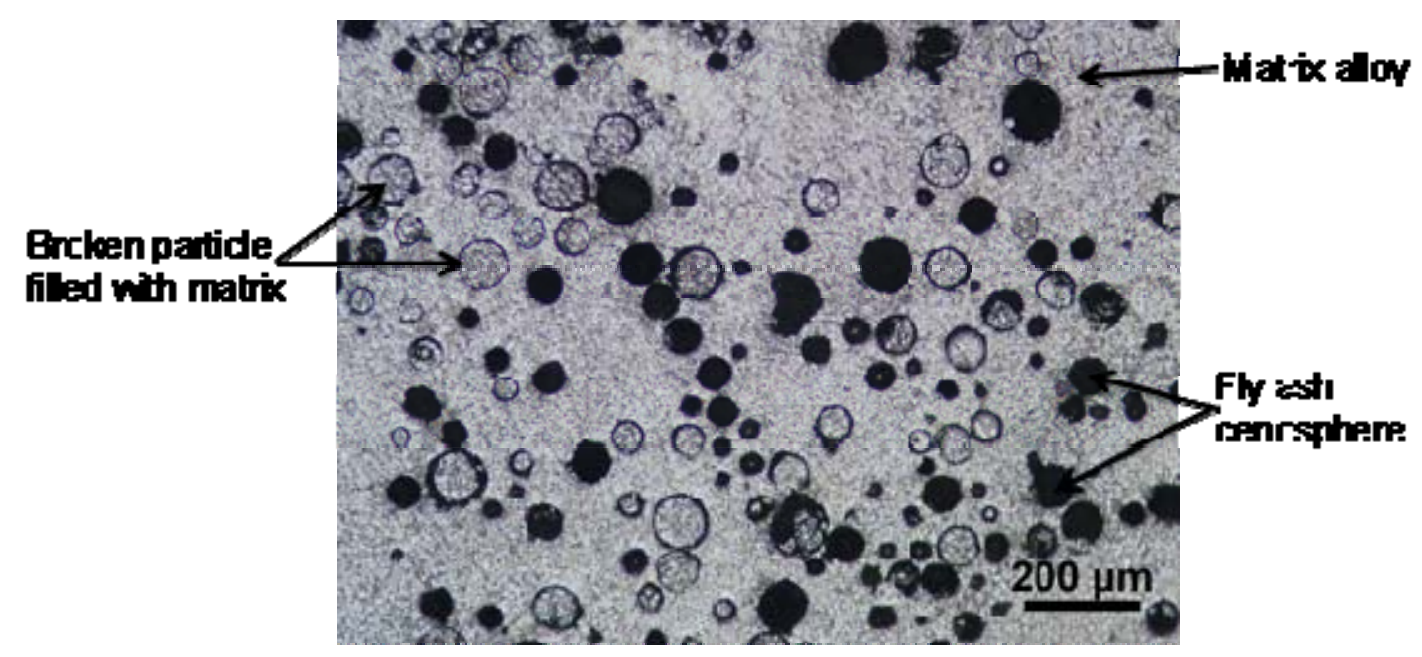

Figure 6. Optical micrograph of AZ91D/fly ash cenosphere composite showing intermetallic precipitates in primary magnesium matrix.

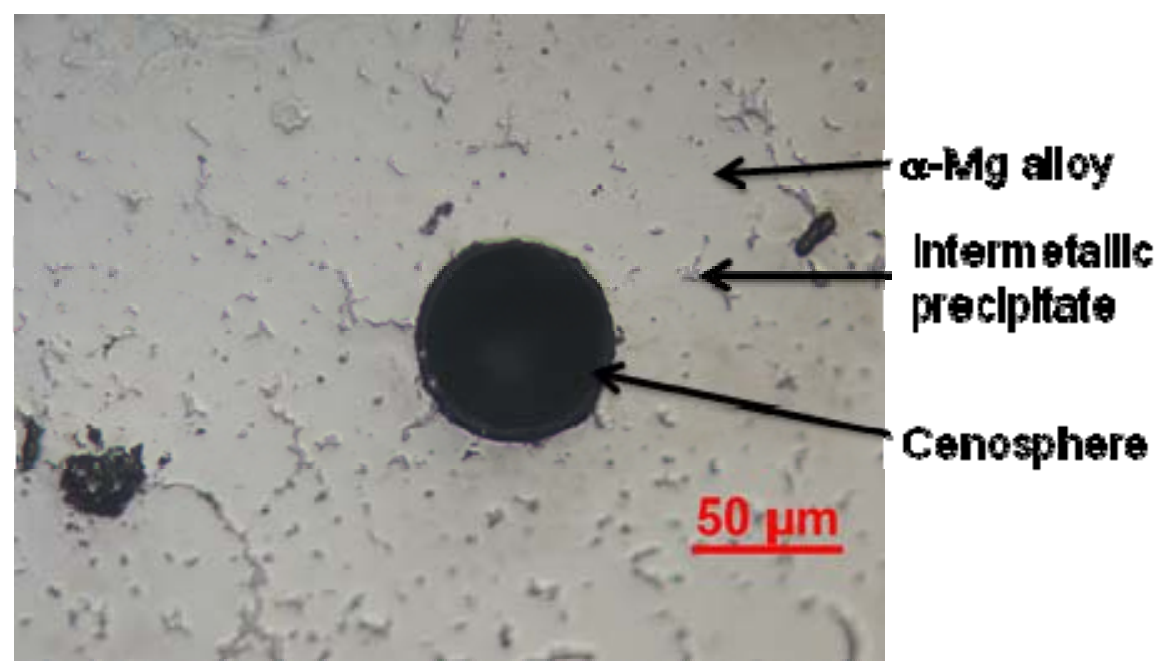


Figure 7. Scanning electron micrograph of AZ91D/fly ash cenosphere composite, where porosity and defects are visible in the cenosphere shell.

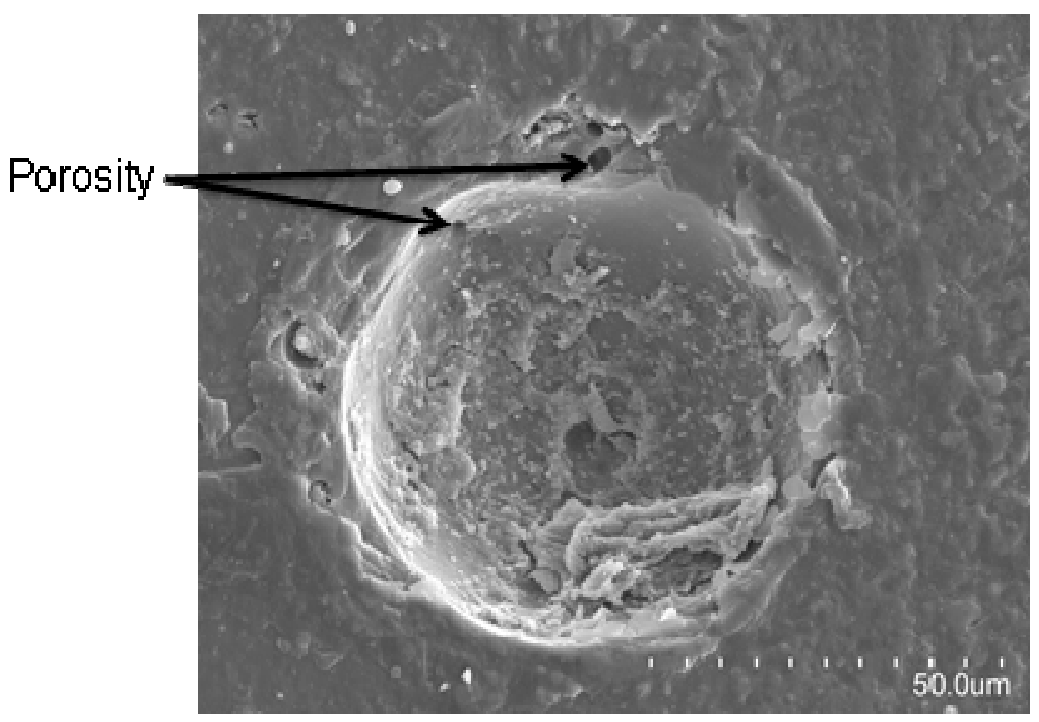

Cenospheres are primarily composed of $\mathrm{SiO}_{2}$ and $\mathrm{Al}_{2} \mathrm{O}_{3}$. Silicon tends to react at the interface with magnesium present in the matrix and form $\mathrm{Mg}_{2} \mathrm{Si}$ and $\mathrm{MgO}$. Thermodynamic calculations show that $\mathrm{MgAl}_{2} \mathrm{O}_{3}$ may also generate, but it reacts with magnesium and decomposes into $\mathrm{MgO}$ and $\mathrm{Al}$.

The microstructure of MMSFs consists of two types of porosity: matrix voids and particle cavities. Both these porosities affect the mechanical properties and density of MMSF. Increase in porosity leads to reduction in strength and modulus. However, the extent of mechanical property reduction due to these types of porosities is different as previously established for polymer matrix syntactic foams [30-32]. Such detailed studies are not yet conducted for MMSF but similar trends may exist.

\section{Mechanical Properties}

The properties of MMSFs depend on a number of parameters-particle shell material, shell wall thickness to diameter ratio, matrix alloy, processing parameters, entrapped voids, and heat treatment conditions. The properties of MMSFs can be normalized with respect to the properties of the matrix alloy processed under similar conditions. However, the effect of porosity is the most significant aspect to understand. In most cases, the densities of aluminum and magnesium matrix MMSFs occur within a narrow range or 1-2.2 $\mathrm{g} / \mathrm{cc}$ and they are expected to compete with each other for applications based on their lower density at the same level of desired mechanical properties. Syntactic foams are designed to be used under compression; therefore, their compressive properties have been extensively studied in the existing literature. Particles are load-bearing elements under compression, which helps in obtaining high modulus and strength by using stiff ceramic particles in the syntactic foam structure. It is also known that the effect of particle-matrix interfacial bonding is much less significant under compression compared to under tension $[33,34]$.

One of the challenges in interpreting and comparing the data obtained from different studies is the definitions used for various mechanical properties. The typical shape of the compressive stress-strain graph for MMSFs is shown by the line marked with A in Figure 8. Four different points are shown in this figure. Point 1 represents $0.2 \%$ yield strength. Point 2 represents the peak strength at the end of the 
elastic region, which is also referred to as plastic stress or compressive strength in some studies. Usually this point is related to damage onset in the material and subsequent reduction in strength and stiffness of the material are observed. Point 3 represents plateau stress and Point 4 represents densification strain, which depends on the total porosity in the material and can be as high as 0.6.

Figure 8. Schematic representation of a typical compressive stress-strain curve for MMSFs.

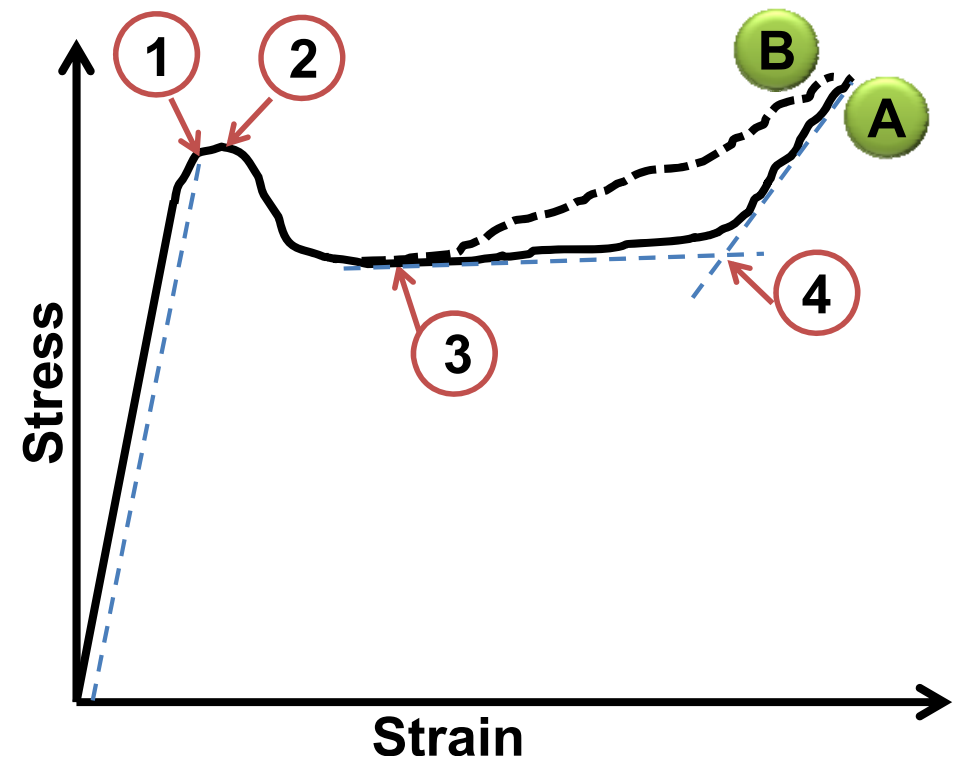

In published studies the yield strength and peak strength are sometimes not distinguished from each other. In reality, the plateau zone may not be nicely defined and the graph may appear similar to the dotted line marked by B in Figure 8. In such case, the interpretation of plateau stress and densification point may widely vary. In addition, composite microstructures may have localized heterogeneities due to the presence of a particle cluster or void, which may lead to considerable variation in results in a batch of specimens from the same source. It should also be noted that the fraction of particles fractured during fabrication is usually not known, which also makes it difficult to estimate the matrix void fraction in the microstructure. Such uncertainties should be remembered while interpreting the results in the following sections. Tensile properties of AZ91D/15 wt $\%$ cenospheres are characterized for specimens processed under five different fabrication conditions, where isothermal temperature and holding time of the slurry before casting are varied in the ranges $720-820{ }^{\circ} \mathrm{C}$ and $15-35 \mathrm{~h}$, respectively [35]. Compared to the ultimate tensile strength (UTS) of the unfilled alloy, $123 \mathrm{MPa}$, the strength of syntactic foams is found to vary in 87-146 MPa for different processing conditions. The specimens processed at $770{ }^{\circ} \mathrm{C}$ and held at $35 \mathrm{~h}$ were found to have the highest strength. These specimens were also tested for tensile properties at $150{ }^{\circ} \mathrm{C}$ and the same trends in UTS were seen [35].

Huang et al. also studied AZ91D/fly ash cenosphere composites. In this work composites containing 4-10 wt\% cenospheres were fabricated and tested for hardness and compressive properties [36]. Their results show that the composite density increased with cenosphere weight fraction. In general, this trend should be reverse and the composite density should decrease as the cenosphere fraction increases because cenospheres are lighter than the matrix. The reverse trend indicates that a large number of cenospheres have fractured during composite fabrication. Fractured cenospheres become higher density solid ceramic particles and result in increased composite density. Due to large scale fracture of 
cenospheres, such composites do not have foam like structure. The compression test results further confirm this observation because all composites have higher strength than the matrix, do not show stress-plateau region, and do not show densification trend in the absence of porous microstructure. These observations indicate that development of process control is very important for such composites. Further, only compressive stress-strain diagrams are provided in this paper. No quantitative or graphical information on modulus, yield strength, or ultimate strength is provided.

The same AZ91D/cenosphere composite MMSF system has been studied in other recent papers [37]. Only one syntactic foam composition is reported in this work, which has the density of $1.23 \mathrm{~g} / \mathrm{cm}^{3}$. The compressive strength is found to be $105.2 \mathrm{MPa}$ in this work, which is lower than the strength of the matrix alloy. An extensive study considering 5-15 wt\% cenospheres in the same alloy system is more useful in understanding the mechanical property trends [38]. The composite density ranged from $1.81 \mathrm{~g} / \mathrm{cm}^{3}$ for the alloy to $1.75 \mathrm{~g} / \mathrm{cm}^{3}$ for $15 \mathrm{wt} \%$ cenosphere composite. The experimental trends on the coefficient of thermal expansion (CTE) did not show any measurable difference between the alloy and the composites. The UTS of alloy was measured as $199 \mathrm{MPa}$, compared to which, the $5 \mathrm{wt} \%$ cenosphere composite had the highest UTS of $215 \mathrm{MPa}$. No necking and yield point were seen in the tensile response of the composites. The modulus of the alloy is measured as $44 \mathrm{GPa}$, compared to which, the composites had consistently lower modulus with increasing fly ash weight fraction. The composite with $15 \mathrm{wt} \%$ cenospheres had a modulus of about $32 \mathrm{GPa}$. The compressive yield strength was found to be lower for composites compared to the matrix. In the absence of standard deviations for experimental data, some of the conclusions are only weakly derived in this work because the values of mechanical properties are relatively close for composites and the alloy [38].

A detailed study is found published on ZC63 matrix syntactic foams containing up to $25 \mathrm{wt} \%$ cenospheres [20]. The compressive modulus decreased from $13.5-11.5 \mathrm{GPa}$ for $0-25 \mathrm{wt} \%$ cenosphere composites. The low modulus for the matrix alloy observed in this study may be a result of porosity in the as-cast specimens. For the same composition range, the ultimate strength varied in the range of 293-348 MPa. The experimental variation in the measured mechanical property data is not presented in this study either, which makes it difficult to draw reliable conclusions because mechanical properties may vary over a large range for composites due to the possible localized inhomogeneities in the composite microstructure.

It is important to put into perspective the mechanical property data for magnesium alloy syntactic foams with other MMSF syntactic foam systems. The compressive properties are extracted from the published studies to the best possible accuracy. These properties are plotted with respect to the composite density for analysis of weight saving advantage.

The compressive property data for aluminum matrix syntactic foams is extracted for comparison from the published studies and plotted in Figure 9 [10,13,14,39-46]. Composites of A2011-T6 alloys show the highest plastic stress, followed by 7075-T6 and 6061 alloy composites. In most cases a clear trend in the data coming from the same study is seen, where plastic stress increases with density. The highest concentration of data is in the density range $1.4-1.7 \mathrm{~g} / \mathrm{cc}$. The plastic stress of aluminum alloy matrix syntactic foams subjected to T6 heat treatment are considerably higher than the corresponding as-cast composites in this group of materials. The magnesium matrix syntactic foams are expected to directly compete with this group of materials. 
Figure 9. Plastic strength of aluminum matrix syntactic foams plotted against density. In the legend the nomenclature refers to the last name of the first author (year) alloy type-heat treatment (strain rate, if used as a parameter).

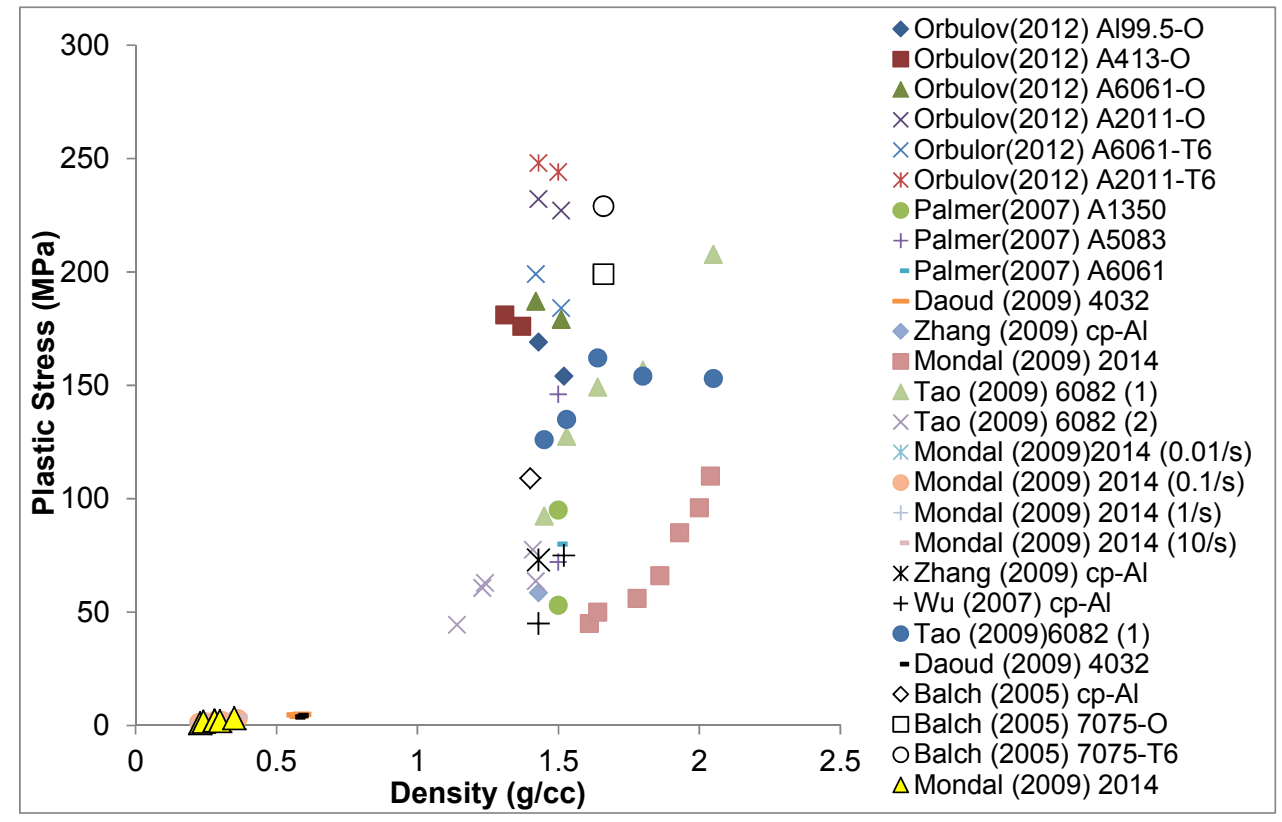

Some syntactic foam composites are found to have less than $0.4 \mathrm{~g} / \mathrm{cc}$ density in Figure 9. These data points belong to foams that contain fly ash cenospheres as well as matrix porosity to create a hybrid foam structure. Such foams are found to have very low strength compared to syntactic foams containing porosity only inside hollow particles.

The yield strength values for various types of MMSFs, including aluminum, titanium, and iron matrix syntactic foams, are plotted in Figure 10 [38,39,43,47-55]. AZ91D and ZC63 matrix syntactic foams are also included in this graph. Yield and plastic strengths are defined by Points 1 and 2, respectively, in Figure 8. In most studies, data for only one of these points is provided for various reasons. In composites containing low particle volume fraction, the plastic stress is not clearly visible and the yield strength is defined. In several other studies, especially those containing high particle volume fractions, the particle fracture starts around plastic stress and the slope of the graph changes rapidly. In such cases, plastic stress values are reported. The difference in the yield and plastic stress is small and the data presented in Figures 9 and 10 can be compared. Some of the outlying data points that have very low stress values should be treated carefully and the material quality and test procedures should be checked in those studies for interpretation.

It can be noticed in Figure 10 that the magnesium matrix syntactic foams have higher values of yield strength compared to most other types of syntactic foams. This is a significant trend for two reasons: (a) the absolute yield strength values for magnesium matrix syntactic foams are among the highest compared to other foams included in this figure; and (b) at the comparable density, the available aluminum matrix syntactic foams have yield strength values from about $30 \%$ to $70 \%$ lower than that of the magnesium matrix syntactic foams. Iron matrix syntactic foams have comparable yield strength but their density is 2-3 higher than the magnesium matrix syntactic foams. This trend demonstrates the possibility of reducing the structural weight by replacing aluminum and titanium matrix syntactic foams with magnesium matrix syntactic foams in some applications. Most of the data 
in Figure 10 fits within a narrow zone, marked by an ellipse and shows the usual trend that yield strength increases with the density of the composite. However, only magnesium matrix syntactic foams break this trend and provide significantly higher strength than other foams of comparable density.

Figure 10. Comparison of yield strength of magnesium, aluminum, zinc, and titanium matrix syntactic foams. In the legend the nomenclature refers to the last name of the first author (year) alloy type (processing pressure, if used as a parameter in the composite synthesis).

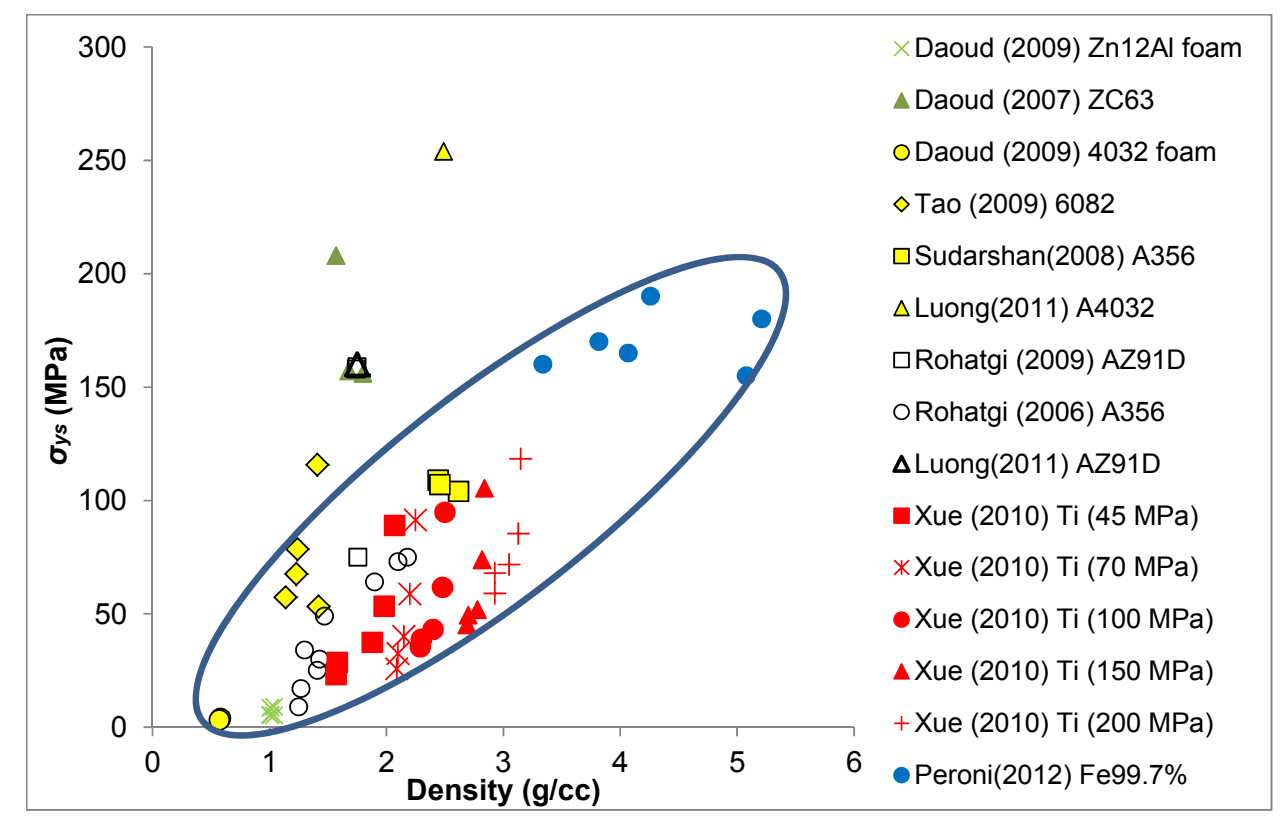

Additional comparison can be conducted between data presented in Figures 9 and 10 by considering plastic stress and yield strength to be comparable as discussed before. In the as-cast condition, magnesium matrix syntactic foams show better properties but the T6 treated aluminum alloys also fall within the same range. The comparison is illustrative of the role of heat treatment in determining the properties of MMSFs. Depending on the other requirements of the applications, such as operating temperature, vibration conditions, CTE, and thermal conductivity, the best material can be selected. The nascent field of magnesium matrix syntactic foams can benefit from this comparison because the data for heat treated compositions is not yet available and further improvement in the properties can be obtained.

\section{Conclusions}

Available studies on magnesium matrix syntactic foams are reviewed in this work. Rapidly increasing interest in magnesium matrix composites, due to their low density, is fueling interest in research and product development. A critical review shows that the understanding of microstructural aspects of magnesium alloys and their composites is well developed now but the mechanical properties are not widely available. Most available studies have characterized up to three compositions of magnesium alloy matrix syntactic foams. In these composites the parameters such as particle density, wall thickness and sometimes, even the weight fraction, are not reported. In the absence of such detailed data, the development of theoretical models is not keeping pace with the experimental work. 
Model validation becomes a significant challenge when the data are not available for a variety of compositions. New techniques such as nanoindentaiton have been used to characterize the mechanical properties of various microstructural phases in magnesium alloys. Availability of this data can help in the future in developing microstructure based models and simulations that can accurately predict the mechanical properties of the alloys and the composites.

When the magnesium matrix syntactic foam data are put into perspective with the mechanical properties of aluminum, titanium, and iron matrix syntactic foams, a clear advantage is observed on the basis of density. Magnesium matrix syntactic foams are among the syntactic foams that have the highest yield strength. The weight saving obtained from the use of these composites to replace components made of solid metals can lead to significant energy saving in automotive and other industrial applications.

Behavior of magnesium matrix syntactic foams under various environmental conditions is not yet studied. This can be significant because the high temperature conditions can lead to reactions between elements present in fly ash cenospheres and the matrix material. Some of the reaction products may be undesirable and adversely affect the long term performance of the composite. AZ series $\mathrm{Mg}-\mathrm{Al}$ alloys used in fabricating syntactic foams have compositions that can be subjected to solution treatment, which can be effectively used to control the mechanical properties and distribution of phases in the composite.

\section{Conflict of Interest}

The authors declare no conflict of interest.

\section{Acknowledgments}

This research was sponsored by U.S. Army Research Laboratory and was accomplished under the Cooperative Agreement W911NF-11-2-0096. The views, opinions, and conclusions made in this document are those of the authors and should not be interpreted as representing the official policies, either expressed or implied, of Army Research Laboratory or the USA Government. The USA Government is authorized to reproduce and distribute reprints for Government purposes notwithstanding any copyright notation herein. Dinesh Pinisetty is thanked for help in manuscript preparation. Oliver M. Strbik III of Deep Springs Technologies (Toledo, OH, USA) is acknowledged for providing hollow ceramic particles for imaging.

\section{References}

1. Rawal, S. Metal-matrix composites for space applications. JOM 2001, 53, 14-17.

2. Hajjari, E.; Divandari, M.; Arabi, H. Effect of applied pressure and nickel coating on microstructural development in continuous carbon fiber-reinforced aluminum composites fabricated by squeeze casting. Mater. Manuf. Proc. 2011, 26, 599-603.

3. Kevorkijan, V.M. Commercial viability of Al-based MMCs in the automotive segment. Mater. Manuf. Proc. 1999, 14, 639-645. 
4. Rohatgi, P.; Weiss, D.; Gupta, N. Applications of fly ash in synthesizing low-cost MMCs for automotive and other applications. JOM 2006, 58, 71-76.

5. Brown, K.; Venie, M.; Woods, R. The increasing use of aluminum in automotive applications. JOM 1995, 47, 20-23.

6. Mordike, B.L.; Ebert, T. Magnesium: Properties-applications-potential. Mater. Sci. Eng. A 2001, 302, 37-45.

7. CAFE Fuel Economy. Available online: http://www.nhtsa.gov/fuel-economy (accessed on 26 June 2012).

8. Guo, R.; Rohatgi, P.; Nath, D. Preparation of aluminium-fly ash particulate composite by powder metallurgy technique. J. Mater. Sci. 1997, 32, 3971-3974.

9. Gupta, N.; Woldesenbet, E.; Mensah, P. Compression properties of syntactic foams: Effect of cenosphere radius ratio and specimen aspect ratio. Compos. A Appl. Sci. Manuf. 2004, 35, 103-111.

10. Balch, D.K.; O’Dwyer, J.G.; Davis, G.R.; Cady, C.M.; Gray, G.T.; Dunand, D.C. Plasticity and damage in aluminum syntactic foams deformed under dynamic and quasi-static conditions. Mater. Sci. Eng. A 2005, 391, 408-417.

11. Dou, Z.Y.; Jiang, L.T.; Wu, G.H.; Zhang, Q.; Xiu, Z.Y.; Chen, G.Q. High strain rate compression of cenosphere-pure aluminum syntactic foams. Scr. Mater. 2007, 57, 945-948.

12. Wu, G.H.; Dou, Z.Y.; Sun, D.L.; Jiang, L.T.; Ding, B.S.; He, B.F. Compression behaviors of cenosphere-pure aluminum syntactic foams. Scr. Mater. 2007, 56, 221-224.

13. Mondal, D.P.; Das, S.; Ramakrishnan, N.; Uday Bhasker, K. Cenosphere filled aluminum syntactic foam made through stir-casting technique. Compos. A Appl. Sci. Manuf. 2009, 40, 279-288.

14. Zhang, Q.; Lee, P.D.; Singh, R.; Wu, G.; Lindley, T.C. Micro-CT characterization of structural features and deformation behavior of fly ash/aluminum syntactic foam. Acta Mater. 2009, 57, 3003-3011.

15. Mukai, T.; Kanahashi, H.; Yamada, Y.; Shimojima, K.; Mabuchi, M.; Nieh, T.G.; Higashi, K. Dynamic compressive behavior of an ultra-lightweight magnesium foam. Scr. Mater. 1999, 41, 365-371.

16. Kanahashi, H.; Mukai, T.; Yamada, Y.; Shimojima, K.; Mabuchi, M.; Aizawa, T.; Higashi, K. Experimental study for the improvement of crashworthiness in AZ91 magnesium foam controlling its microstructure. Mater. Sci. Eng. A 2001, 308, 283-287.

17. Wen, C.E.; Yamada, Y.; Shimojima, K.; Chino, Y.; Hosokawa, H.; Mabuchi, M. Compressibility of porous magnesium foam: Dependency on porosity and pore size. Mater. Lett. 2004, 58, 357-360.

18. Solórzano, E.; Hirschmann, M.; Rodriguez-Perez, M.A.; Körner, C.; de Saja, J.A. Thermal conductivity of AZ91 magnesium integral foams measured by the Transient Plane Source method. Mater. Lett. 2008, 62, 3960-3962.

19. Hartmann, M.; Reindel, K.; Singer, R.F. Fabrication and properties of syntactic magnesium foams. In Proceedings of the 1998 MRS Spring Meeting, San Francisco, CA, USA, 13-17 April 1998; pp. 211-216.

20. Daoud, A.; Abou El-khair, M.T.; Abdel-Aziz, M.; Rohatgi, P. Fabrication, microstructure and compressive behavior of $\mathrm{ZC}_{63} \mathrm{Mg}$-microballoon foam composites. Compos. Sci. Technol. 2007, 67, 1842-1853. 
21. Meng, X.F.; Li, D.H.; Shen, X.Q.; Liu, W. Preparation and magnetic properties of nano-Ni coated cenosphere composites. Appl. Surf. Sci. 2010, 256, 3753-3756.

22. Meng, X.F.; Shen, X.Q.; Liu, W. Synthesis and characterization of Co/cenosphere core-shell structure composites. Appl. Surf. Sci. 2012, 258, 2627-2631.

23. Károly, Z.; Szépvölgyi, J. Hollow alumina microspheres prepared by RF thermal plasma. Powder Technol. 2003, 132, 211-215.

24. Hyodo, T.; Murakami, M.; Shimizu, Y.; Egashira, M. Preparation of hollow alumina microspheres by microwave-induced plasma pyrolysis of atomized precursor solution. J. Eur. Ceram. Soc. 2005, 25, 3563-3572.

25. Watanabe, M.; Yamashita, H.; Chen, X.; Yamanaka, J.; Kotobuki, M.; Suzuki, H.; Uchida, H. Nano-sized Ni particles on hollow alumina ball: Catalysts for hydrogen production. Appl. Catal. Environ. 2007, 71, 237-245.

26. Gupta, M.; Sharon, N.M.L. Magnesium, Magnesium Alloys, and Magnesium Composites; John Wiley \& Sons: Hoboken, NJ, USA, 2011.

27. Gupta, N.; Luong, D.D.; Rohatgi, P.K. A method for intermediate strain rate compression testing and study of compressive failure mechanism of Mg-Al-Zn alloy. J. Appl. Phys. 2011, 109, $103512-103517$.

28. Kamieniak, J.; Zydek, A.; Braszczynska-Malik, K.N. Aluminosilcate glass cenospheres as a component of cast magnesium matrix composites. Arch. Foundry Eng. 2011, 11, 109-112.

29. Huang, Z.; Yu, S. Microstructure characterization on the formation of in situ $\mathrm{Mg}_{2} \mathrm{Si}$ and $\mathrm{MgO}$ reinforcements in AZ91D/Flyash composites. J. Alloy. Compd. 2011, 509, 311-315.

30. Porfiri, M.; Gupta, N. Effect of volume fraction and wall thickness on the elastic properties of hollow particle filled composites. Compos. B Eng. 2009, 40, 166-173.

31. Aureli, M.; Porfiri, M.; Gupta, N. Effect of polydispersivity and porosity on the elastic properties of hollow particle filled composites. Mech. Mater. 2010, 42, 726-739.

32. Gupta, N.; Ye, R.; Porfiri, M. Comparison of tensile and compressive characteristics of vinyl ester/glass microballoon syntactic foams. Compos. B Eng. 2010, 41, 236-245.

33. Tagliavia, G.; Porfiri, M.; Gupta, N. Analysis of hollow inclusion-matrix debonding in particulate composites. Int. J. Solids Struct. 2010, 47, 2164-2177.

34. Tagliavia, G.; Porfiri, M.; Gupta, N. Elastic interaction of interfacial spherical-cap cracks in hollow particle filled composites. Int. J. Solids Struct. 2011, 48, 1141-1153.

35. Huang, Z.; Yu, S.; Liu, J.; Zhu, X. Microstructure and mechanical properties of in situ $\mathrm{Mg}_{2} \mathrm{Si} / \mathrm{AZ91D}$ composites through incorporating fly ash cenospheres. Mater. Des. 2011, 32, 4714-4719.

36. Huang, Z.Q.; Yu, S.R.; Li, M.Q. Microstructures and compressive properties of AZ91D/fly-ash cenospheres composites. Trans. Nonferrous Met. Soc. China 2010, 20, s458-s462.

37. Liu, J.A.; Yu, S.R.; Huang, Z.Q.; Ma, G.; Liu, Y. Microstructure and compressive property of in situ $\mathrm{Mg}_{2} \mathrm{Si}$ reinforced $\mathrm{Mg}$ - microballoon composites. J. Alloy. Compd. 2012, in press.

38. Rohatgi, P.K.; Daoud, A.; Schultz, B.F.; Puri, T. Microstructure and mechanical behavior of die casting AZ91D-Fly ash cenosphere composites. Compos. A Appl. Sci. Manuf. 2009, 40, 883-896.

39. Daoud, A. Effect of fly ash addition on the structure and compressive properties of 4032-fly ash particle composite foams. J. Alloy. Compd. 2009, 487, 618-625. 
40. Mondal, D.P.; Goel, M.D.; Das, S. Compressive deformation and energy absorption characteristics of closed cell aluminum-fly ash particle composite foam. Mater. Sci. Eng. A 2009, 507, 102-109.

41. Mondal, D.P.; Goel, M.D.; Das, S. Effect of strain rate and relative density on compressive deformation behaviour of closed cell aluminum-fly ash composite foam. Mater. Des. 2009, 30, $1268-1274$.

42. Tao, X.F.; Zhang, L.P.; Zhao, Y.Y. Al matrix syntactic foam fabricated with bimodal ceramic microspheres. Mater. Des. 2009, 30, 2732-2736.

43. Tao, X.F.; Zhao, Y.Y. Compressive behavior of Al matrix syntactic foams toughened with Al particles. Scr. Mater. 2009, 61, 461-464.

44. Balch, D.K.; Dunand, D.C. Load partitioning in aluminum syntactic foams containing ceramic microspheres. Acta Mater. 2006, 54, 1501-1511.

45. Orbulov, I.N.; Ginsztler, J. Compressive characteristics of metal matrix syntactic foams. Compos. A Appl. Sci. Manuf. 2012, 43, 553-561.

46. Palmer, R.A.; Gao, K.; Doan, T.M.; Green, L.; Cavallaro, G. Pressure infiltrated syntactic foams: Process development and mechanical properties. Mater. Sci. Eng. A 2007, 464, 85-92.

47. Daoud, A. Effect of strain rate on compressive properties of novel $\mathrm{Zn}_{12} \mathrm{Al}$ based composite foams containing hybrid pores. Mater. Sci. Eng. A 2009, 525, 7-17.

48. Daoud, A.; Abou El-khair, M.T.; Abdel-Aziz, M.; Rohatgi, P. Fabrication, microstructure and compressive behavior of $\mathrm{ZC}_{63} \mathrm{Mg}$-microballoon foam composites. Compos. Sci. Technol. 2007, 67, 1842-1853.

49. Rohatgi, P.K.; Kim, J.K.; Gupta, N.; Alaraj, S.; Daoud, A. Compressive characteristics of A356/fly ash cenosphere composites synthesized by pressure infiltration technique. Compos. A Appl. Sci. Manuf. 2006, 37, 430-437.

50. Xue, X.B.; Zhao, Y.Y.; Kearns, V.; Williams, R.L. Mechanical and biological properties of titanium syntactic foams. In Proceeding of the TMS 2010 Annual Meeting \& Exhibition, Seattle, WA, USA, 14-18 Febuary 2010; pp. 129-135.

51. Xue, X.; Zhao, Y. Ti matrix syntactic foam fabricated by powder metallurgy: Particle breakage and elastic modulus. JOM 2011, 63, 43-47.

52. Sudarshan, S.M.K. Synthesis of fly ash particle reinforced A356 Al composites and their characterization. Mater. Sci. Eng. A 2008, 480, 117-124.

53. Peroni, L.; Scapin, M.; Avalle, M.; Weise, J.; Lehmhus, D. Dynamic mechanical behavior of syntactic iron foams with glass microspheres. Mater. Sci. Eng. A 2012, 552, 364-375.

54. Luong, D.; Gupta, N.; Rohatgi, P. The high strain rate compressive response of Mg-Al alloy/fly Ash cenosphere composites. JOM 2011, 63, 48-52.

55. Luong, D.; Gupta, N.; Daoud, A.; Rohatgi, P. High strain rate compressive characterization of aluminum alloy/fly ash cenosphere composites. JOM 2011, 63, 53-56.

(C) 2012 by the authors; licensee MDPI, Basel, Switzerland. This article is an open access article distributed under the terms and conditions of the Creative Commons Attribution license (http://creativecommons.org/licenses/by/3.0/). 